\title{
Internal Audit and Risk Management of Internet Finance Enterprise
}

\author{
Lan Xiang Xingyu Mu
}

School of Finance, Guizhou University of Finance and Economics, Guiyang Guizhou 550025 , China

\begin{abstract}
Margin trading in March 31, 2010 officially launched in China, and in 2011 October began to turn to the conventional business. Financing business is the development of a new business better, for the whole development of the securities market with huge opportunities for investors and companies to bring a win-win situation. However, in the market scale at the same time the risk, the attendant problems, the risk prevention and control ability of the company to put forward higher requirements. Based on the experimental study of CITIC's orientation, risk analysis of securities companies may face in financing securities, and to put forward some suggestions and Countermeasures on how to prevent the risk.
\end{abstract}

\section{Keywords}

Risk Management; Margin Trading; CITIC Securities.

\section{中信证券公司融资融券业务风险控制研究}

向叐 穆星宇

贵州财经大学金融学院, 贵州贵阳 550025, 中国

摘要：我国在 2010 年 3 月 31 日正式启动融资融券交易，并于 2011 年的 10 月份开始转向常 规业务。融资融券业务是目前发展较好的一项新兴业务，为整个证券市场的发展带了巨大的 机遇，也为投资者和公司带来了双赢。然而，在市场规模扩大的同时，风险问题也随之而来， 这就对公司的风险防控能力提出了更高的要求。本文以中信公司的具体研究为导向, 分析证 券公司在开展融资融券业务时可能面临的风险，并对如何防范风险提出建议和对策。

关键词 : 风险管理; 融资融券; 中信证券

1. 融资融券业务相关理论

\section{1. 融资融券业务的内涵}

融资融券是指投资者向具有证券 交易所会员资格的证券公司提供担保
物，借入资金买入本所上市证券或借 入本所上市证券并卖出的行为。

融资融券可分为两部分：一部分 是融资的过程，即用借钱的方式买股 票；另一部分的融券是指卖掉证券来 
取得日后归还股票的资金。

\section{2 融资融券业务的特征}

第一，本质是信用交易。

从融资融券交易的过程来看，投 资者首先申请开户，随后进入信用交 易及债务清偿等融资融券的交易过程， 具体如下: 向证券公司提出交易请求, 并递交申请材料; 证券公司针对申请 者进行业务资格的初次审核。通过业 务资格审核后，证券公司将开展征信 业务工作。对客户的财产、身份及其 收入状况、投资及风险偏好等问题进 行全方位的了解, 对其信用状况进行 测评，授信额度及各项利息费用都能 由此确定。

第二，本质是担保交易。

融资融券业务与当下普通证券交 易有所不同, 主要体现在融资融券是 信用交易的一种主要形式。投资者对 于证券的买入和卖出并不是使用自己 的资金，而是通过借贷得到的，但是 这种借贷也需要缴纳一定的保证金来 保证后期的还款能力。国外通常将保 证金的法律属性定性为让与担保, 并 由此引申一系列的制度安排。但在我 国现有的物权法律制度体系中，尚未 引入让与担保的概念, 只有质押制度。 质押制度虽允许股权等权利质押，但 是，如果将保证金定性为权利质押， 则需要进行质押登记。

第三，融资融券具有财务杜杆性 质。

我们所说的融资交易常常是指买 空, 而融券交易则相反, 往往是指卖 空。在融资融券业务进行中，倘若投 资者因价格的问题而出现暂时性的短 缺时, 可以向证券公司借取一定的资 金来买入证券，而当出现市场波动时， 可以将证券卖出, 待证券价格在谷底 时再买回，归还给证券公司来支付前 期的借款。这种方法不仅改变了市场
原有的单边获利模式、拓宽投资者盈 利业务, 同时也增加了利润和减小了 相应的损失。

\section{3 融资融券业务对证券公司的影响}

第一, 增加盈利性收入

当前中国经济处于新常态，产业 结构不断升级, 内需持续扩大, 新兴 经济体不断产生, 在此背景下, 我国 中小型证券公司面临转型, 转变为轻 资本业务发展 ${ }^{[1]}$ 。基于经济增长放缓的 担忧，监管下的巨大资本压力，证券 公司强化资本约束意识, 利用资本市 场提高其资本充足率; 优化表内表外 资产结构, 合理配置其规模, 防止盲 目扩张; 证券公司应加大对融资融券 业务的配置力度, 提供多元化的经纪 业务, 为证券公司提供新的利润增长 点。

第二，促进产品创新

未来证券公司要向轻资本业务发 展模式转型, 基于这样的前提下证券 公司必须增加相应融资业务产品，特 别是融资融券这方面的产品。目前, 国内现有的证券公司理财产品总体的 特征变现为自主研发能力差, 缺乏创 新, 普遍模仿国外产品。证券公司目 前推出理财产品的目的仍在于防止投 资流入他行，并不能真正意义上将理 财产品变成公司收入的一部分。

证券公司要想促进轻资本证券业 务的发展必须重新设计自己的理财产 品和其他金融服务, 将市场进行细分, 针对潜在的消费对象利用市场调查的 方式为客户定制符合他们需求的理财 产品, 从而使融资融券业务成为证券 公司在新常态经济强下的一种强有力 后备支持, 弥补因利率市场化进程中 所受到的资金损失。 


\section{2. 中信证券公司融资融券业务}

\section{1 融资融券业务的开展情况}

我国自 2010 年 3 月开展融资融券 业务以来, 目前最早开展此业务的券 商主要有中信证券、国泰君安等券 商, , 随着近些年来的不断发展和进 步，给我国融资融券业务注入了新兴 的力量。从 2006 年到现在, 融资融券 标的证券已经超过了 700 只 ${ }^{[2]}$ 。另外, 我国证券市场融资融券总余额也在不 断增长, 目前已经突破了万亿元。融 资融券业务在我国正从一项创新交易 逐渐向常规性交易演变, 融资融券业 务的市场需求和发展潜力得到进一步 的释放, 融券业务相较于融资业务而 言规模较小, 发展速度也慢, 整体上 属于不均衡的发展状态。

在融资融券行业内, 中信证券是 发展情况最佳的公司之一，在依法获 得融资融券资格后, 用先进、科学的 融资融券交易体系向客户提供服务, 依法办理融资业务, 在客户向证券公 司卖出证券的交易中, 一定程度上降 低了经营活动的风险, 使得中信证券 的融资融券业务发展领先业内其他公 司, 得到客户的信任和青睐。

中信证券公司的融资业务主要针 对的是中小企业的股权融资业务，为 此, 中信公司专门设立了专门的融资 线, 为中小企业提供了完善且全程的 业务服务，来帮助中小企业实现自身 的转型和发展。

下图是中信证券公司融资融券业 务交易的流程展示:

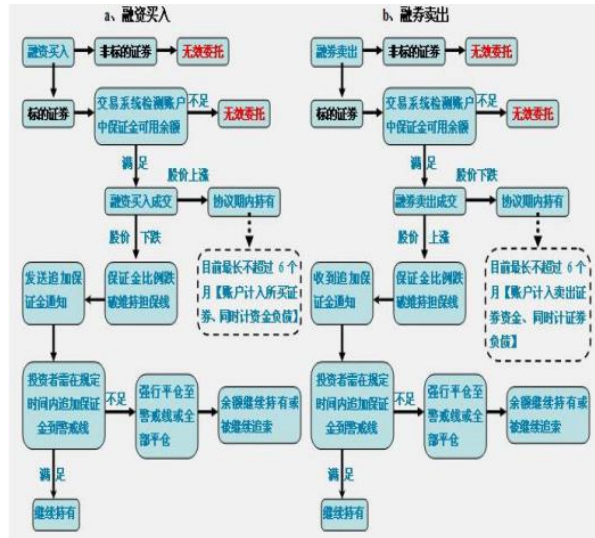

\section{2 融资融券业务风险}

第一，客户信用风险

中信证券融资融券业务开展的关 键征信环节, 只有严把此关, 才能减 小或者规避风险, 避免造成巨大的损 失。从中信证券往往通过多种方式审 核, 例如信用额度审批、逐日盯市等 方法实现有效的规避和防控。

\section{第二，市场风险}

市场的不可预测和防空的风险带 来大幅波动, 被称为市场风险。由于 受资本市场的影响, 股价会出现严重 的波动状况, 这种情况的出现势必会 增加风险, 并且给市场交易的主体带 来风险, 难以与市场进行对抗, 也无 法预测市场。

\section{第三，业务规模风险}

这主要是指规模失控的情况出现, 即单个客户长时间、大规模的占用公 司的融资融券资源，从而造成公司资 金流动性问题和资本规模比例的失衡。 证券信用交易具有对证券交易量放大 的作用, 证券公司为获取利益, 会逐 步扩大业务规模。从中信证券的发展 中就可以看出这种趋势, 中信证券公 司作为证券交易中的资金或证券的提 供者, 其客户的数量越大, 其规模也 就越大, 所以其所要承担的风险也就 越大。 
第四，法律法规及监管风险

在进行融资交易的时候，往往可 能由于行情不景气等原因, 证券公司 就会强行平仓, 并且将平仓后的证券 大幅卖出造成巨大的反弹情况的出现。 因此, 证券公司的这种行为有时会和 投资者产生巨大的纠纷和矛盾, 并且 有时会出现诉讼和索赔的状况出现, 这就迫切的要求我们要实施法律法规 来规避风险，形成监管的局面。

\section{3. 中信证券融资融券业务风险管理问 题}

\section{1 客户信用风险管理问题}

证券公司根据客户的信用程度来 决定客户的授信程度。客户信用能力 不足或客户自身决策带来的信用风险, 即违约风险的出现 ${ }^{[3]}$ 。证券公司必须牢 牢把关客户信用的评估工作, 确定客 户融资融券的额度、融资利息及融券 费率的大小, 才能有效的规避这类风 险。

\section{2 市场风险管理问题}

融资融券业务中的市场风险管理 问题是指, 在实行非强制型, 实行无 差别费率的融资融券业务时, 经营状 况不好的证券公司将纷纷加入, 而系 统风险极低的大型证券公司有可能会 主动脱离该体系。而为了继续维持融 资融券体系的运行, 同时满足那些经 营状况不好的证券公司的支出需要, 保险费率会随着系统风险极低的大证 券公司的相继退出而继续上升。

\section{3 业务规模风险管理问题}

融资融券业务是综合性业务, 需 要操作人员不仅要对其经营的网络业 务有全面细致的了解, 了解风险和收 益, 也要对行业以及企业内部的具体
情况了解。并且对从业人员的专业知 识和技术提出了较高的要求 ${ }^{[4]}$ 。

\section{4. 中信证券融资融券业务风控防范的 具体对策和措施}

\section{1 客户信用风险防范}

\author{
第一，降低对客户融资融券资金 \\ 额度
}

客户资产，负债，交易习惯，信 用状况和对股权集中度的信息综合分 析等方面的比例高低, 间接风险各方 面的大小, 客户的风险承受能力高低 等方面都与整体的风险承受能力有关。 全面提升相应的全面的实用的投资者 教育, 加大宣传力度保证金合同和 “买者自负” 的原则, 鼓励投资者理 性适度的参与两融交易, 而不能盲目 的追涨杀跌，同时降低融资融券资金 额度, 减少本公司客户信用风险同时 也保护了投资者的利益。

\section{第二，设立客户违约准备金}

证券公司的客户违约金管理的策 略, 必须符合证券公司的实际运行情 况以及外部市场环境, 同时也要反映 出证券公司的未来发展格局和发展方 向。也就是说, 客户违约金管理策略 的制定是一个多方面的综合行为, 因 此, 根据中信证券的实际运行情况, 由此认为, 中信证券证券公司应提倡 针对 20\%的核心客户提供个性化服务, 使之成为客户违约金管理的目标对象, 对证券公司中占大部分比例的其他客 户提供星级服务。只有通过这么做, 才能将其的资源做到充分的利用。有 利于中信证券证券公司更好的制定因 人而异、恰到好处的个性化服务。

\section{2 市场风险防范}

我国整体社会信用环境较国外发 达国家就存在一定差距，而在高风险、 流动性的情况下经营就变得更加严重, 
这与对相关从业人员法律知识普及较 少，和没有完善的风险管理策略机制 有着不可分割的联系; 另外部分融资 融券业务证券公司观念薄弱, 逃避债 务的现象仍较普遍, 尤其是出现自身 经营不善等问题时，有的贷户往往赖 账不还，导致证券公司不良融券业务 持续上升，既影响了证券公司融券业 务的持续投入，也对证券公司未来的 工作开展带来很大的发展阻力 ${ }^{[5]}$ 。

证券公司作为我国最重要的金融 机构之一, 盈利性是其发展的根本目 标, 它们在进行融券业务时也必然会 进行有关的风险评估, 而在现阶段下 新兴企业融券业务上就存在许多风险。

一是像高新技术企业这样的新兴企业 缺乏必需的抵押担保物, 知识产权和 构想等无法用货币来衡量，而其支持 对象又是未知的潜在市场, 其风险程 度更大；二是存在道德风险，近年来 存融券业务企业意识的缺失使部分企 业主观上往往没有及时还贷的意愿, 而针对追帐过程中的风险问题, 一定 程度上给公司追回账款带来很大的阻 碍。

因此制定合理完整的证券公司风 险管理策略和政策是必须的, 一个良 好的风险管理机制能够提醒预警资产 充足率和不良融券业务率等指标的违 规与否情况, 风险管理策略的制定应 该是层层预警, 自下而上, 下到证券 公司填单、柜台业务，上到企业巨额 融券业务的审批，都应该具有完善的 机制, 进而防止各种不必要的损失。

\section{3 业务规模风险防范}

伴随着我国金融市场发展的良好 化, 迫使我国的金融机构必须要加大 整顿力度, 但是通过具体的比较可以 看出, 我国对于证券公司的关注度和 改革力度都是较弱的, 并且还存在许 多问题。由于证券公司多年来在企业
存融券业务方面发挥着主力作用, 但 因为在历史上遗留的各种问题，导致 了企业内的产权难以划分清楚而且政 策总是不断地在变更, 这些因素都为 证券公司的发展带来了巨大的影响, 导致许多公司存有大量的不良资产和 坏账。另一方面, 社会公众受教育水 平明显提升, 投资需求也越来越大, 对金融服务要求越来越高, 而证券公 司人员数量和素质越来越难以适应新 形势下的工作需要, 管理制度存在漏 洞等都影响这证券公司业务发展的良 好开展。

另外, 证券公司作为收益较为稳 定金融机构之一, 追求盈利性是其经 营和提升的根本目的。在融券业务发 放问题上，它们同其他金融机构一样 倾向于发放安全性较高, 客户资源良 好的融券业务。但在现在的经济环境 中, 证券公司数目众多, 为了在激烈 的竞争中站稳脚跟, 又不得不支持许 多风险程度高或发展前景不明朗的高 科技项目或者创业项目, 这就使得自 身的盈利性大打折扣。纵观我国证券 公司金融发展史，不难发现我国证券 公司由于资历尚浅缺乏严谨而高效的 风险管理组织架构, 导致流动性风险 增加，资金安全性大大降低。

\section{4 法律法规及监管风险防范}

相关部门应积极完善我国融资融 券业务相关法律条文, 即采用对现有 法律条文进行修改和补充的方法, 对 未来市场可能出现的假想风险进行提 前预防, 并在未发生之前做出相应的 防范, 做到防范于未然, 减少违法和 犯罪的产生。当前融资融券的法律问 题最突出的是非法集资、非法融资问 题, 以 P2P 和众筹表现得最为突出。 中国人民银行应当与银行、证券、保 险监管机构联手, 落实相关监管措施, 使得融资融券产品的投资风险得到充 
分的披露，坚决禁止非法融资活动， 尤其是 P2P 平台的资金池问题，不能 集担保、借贷于一体, 不能让融资融 券企业通过虚拟平台避开法律的规定， 既做裁判员又做运动员。

\section{参考文献}

[1]陈丽贞. 融资融券业务对证券公司 影响及风险控制 $[\mathrm{J}]$. 科技经济导 刊, 2016, 18:167-168.

[2]汪思冰, 沈思猛. 证券公司融资融 券业务面临的风险及防范 $[J]$. 技 术与市场, 2014, 08:320-321.

[3] 孙唐菲. 基于 SOM 网络的融资融券 个人客户信用风险管理研究 [D]. 北京: 首都北京贸易大学, 2011 .

[4]袁奇. 证券公司融资融券业务的风 险管理 [D]. 天津: 天津大学, 2012 .

[5]陈沁梅. 防范融资融券业务风险的 对策建议 $[J]$. 经济研究导 刊, 2011, 08:109-110. 